\title{
Glasobjekte im höfischen Kontext. Produktion, Nutzung und Wirkung in der Frühen Neuzeit (1500-1800) Konferencja naukowa, Rudolstadt, 21-23 listopada 2019
}

dniach 21-23 listopada 2019 roku na zamku Heidecksburg (Rudolstadt, Turyngia) odbyła się konferencja naukowa poświęcona przedmiotom szklanym w kręgu dworskim - ich produkcji i zastosowaniu w czasach nowożytnych. Organizatorem sesji było stowarzyszenie Rudolstädter Arbeitskreises zur Residenzkultur, założone 20 lat wcześniej i tym samym świętujące swój jubileusz. Czynny udział w obradach wzięli badacze barokowej architektury i rzemiosła artystycznego z licznych ośrodków niemieckich (m.in. z Drezna, Arnstadt, Berlina, Poczdamu, Düsseldorfu, Kolonii, Monachium, Karlsruhe) i zagranicznych (wśród nich np. z Wilna, Berna, Salzburga). Uroczystego powitania gości dokonali przedstawiciele grupy roboczej z Matthiasem Müllerem - prezesem Rudolstädter Arbeitskreises - na czele. Słowo wstępne do gości skierowali także: dyrektor Muzeum-Zamku Heidecksburg Lutz Unbehaun, dyrektor Stiftung Thüringer Schlösser und Gärten Doris Fischer oraz Annette Cremer (Gießen).

Pierwszy panel poświęcony był formie i funkcji szklanych elementów dopełniających architekturę i wystrój wnętrz - okien, luster czy żyrandoli. Inauguracyjny referat Petera Heinricha Jahna (Drezno) pt. Der Dresdner Zwinger - eine barocke, Glasarchitektur podejmował problematykę europejskiej genezy przeszkleń wprowadzonych przez M.D. Pöppelmanna w Zwingerze. Nie zabrakło porównań m.in. z wersalskim Grand Trianon. Antje Vanhoefen (Arnstadt) w wystąpieniu Schmelz - Glasperlen als Ausstattungselemente höfischer Interieurs zobrazowała fenomen mody na okładziny ścienne zdobione haftem ze szklanymi koralikami. Interesująco prezentowały się też powiązania handlowe mających siedzibę pod Paryżem 


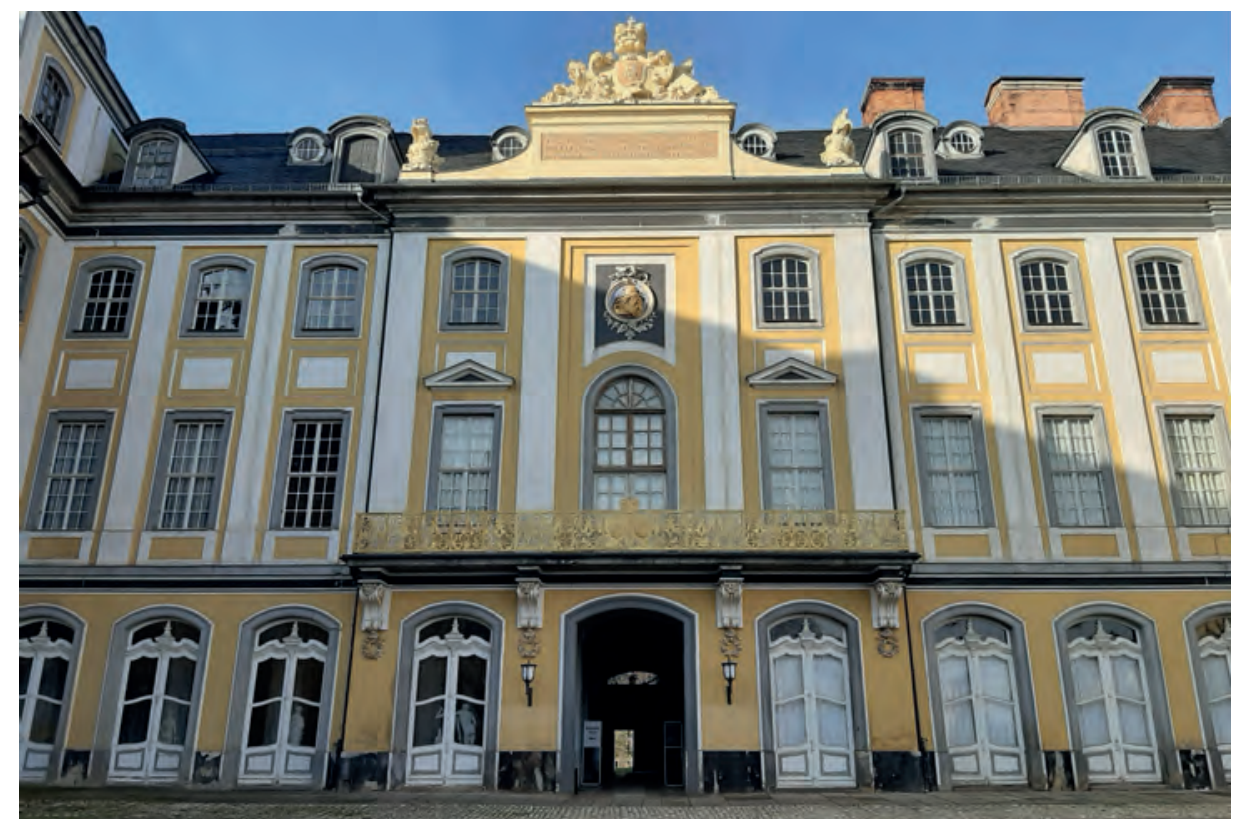

1. Rudolstadt, zamek Heidecksburg, fot. autorka, 2019

sprzedawców dóbr luksusowych. Wątek ten został scharakteryzowany w odczycie Martina Pozsgaia (Darmstadt) Der Pariser mirotier marchand Charles Granier als Lieferant von Spiegelglas an deutsche Fürstenhöfe. Następnie głos zabrała Käthe Klappenbach (Berlin) z prezentacją Die "gläsernen Cronen" - Glasarmkronleuchter aus europäischen Glashütten, stanowiącą studium form artystycznych żyrandoli ze szklanymi ramionami. Z kolei Margret Scharrer (Berno) w prelekcji Gläserne Klänge dowiodła szczególnej popularności szklanych instrumentów muzycznych w Turyngii w XVII i XVIII stuleciu. Panel zamknęła Verena Wasmuth (Poczdam) z tekstem Champagnerflöten am preußischen Hof. Tafelkultur und Luxusgläser im 18. Jahrhundert. Badaczka zmierzyła się z tezą o użytkowaniu konkretnego typu brandenburskich kieliszków do szampana na pruskim dworze i zarysowała szerszą problematykę tzw. kultury stołowej czasów baroku.

Czwartkowe obrady uwieńczył wieczorny wykład Goldrubin - ein alchemistischer Kunststoff, który wygłosił znawca znaczenia szkła w sztuce na przestrzeni epok - Dedo von Kerssenbrock-Krosigk (Düsseldorf). Badacz zaprezentował wprowadzenie do produkcji artystycznej szkła rubinowego, wytwarzanego wedle receptury stworzonej w 1670 roku przez poczdamskiego alchemika Johanna von Löwenstern-Kunckela.

Drugi dzień obrad rozpoczął się sekcją poświęconą produkcji szkła. Dzięki tekstowi Die Glashütten in der Mark Brandenburg in der ersten Hälfte des 17. Jahrhunderts, który przedstawił Markus Leo Mock (Poczdam), scharakteryzowana została jedna z najstarszych gałęzi przemysłu funkcjonujących na obszarze Brandenburgii, 


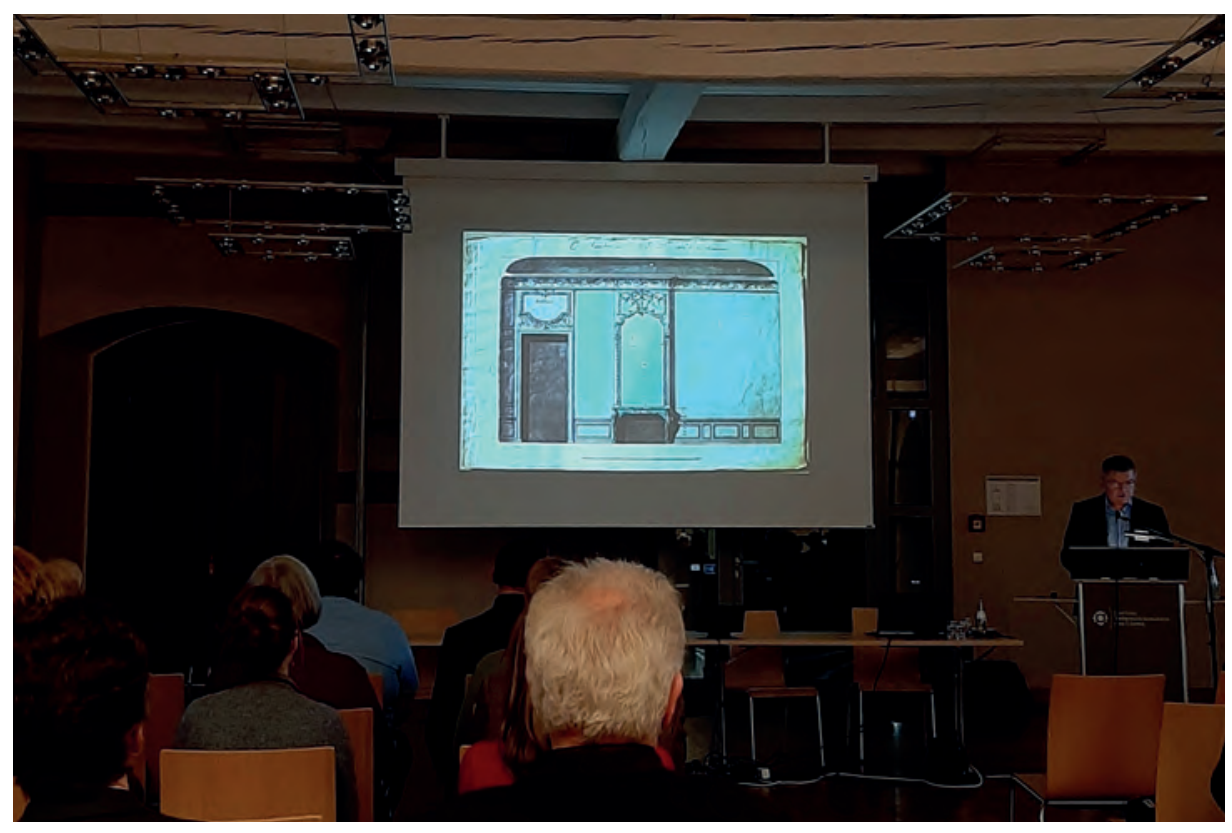

2. Obrady konferencyjne w Rudolstadt, fot. autorka, 2019

sięgająca swą genezą XVI stulecia. Następnie Reinhold Reith (Salzburg) w referacie Ein "geschenktes Handwerk"? Das Handwerk der Glaser in der frühen Neuzeit podjął próbę wyjaśnienia sposobu funkcjonowania warsztatów, naboru czeladników i wreszcie handlu wyrobami szklanymi w XVII wieku. Przedmiotem rozważań Lisy Woop (Erfurt), zawartych w wystąpieniu Die Präsentation der Glasmacher beim Herrscherempfang Heinrichs III. 1597 in Venedig, był z kolei pokaz słynnego szkła wytwarzanego na wyspach Murano podczas - przywołanej w tytule - wizyty Henryka III w Wenecji.

Popołudniowy panel ukazywał wyniki najnowszych badań nad technikami dekoracyjnymi. Sabine Tiedtke (Gießen) w odczycie Glasschnitt im 17. Jahrhundert dokonała przeglądu szlifów norymberskich. Potem głos zabrała Triin Jerlei (Wilno), która w referacie Artists as inventors. Heinrich Schwanhardt's accidental discovery of acid-etching ( $17^{\text {th }}$ century) skoncentrowała się na odkryciu i wprowadzeniu do produkcji wyrobów szklanych techniki trawienia kwasem. Z kolei Elisa Ambrosio (Romont/Schweiz) w wystąpieniu Täuschung und Spielerei in der Hinterglasmalerei des frühen 17. Jahrhunderts przybliżyła uczestnikom konferencji sposoby uzyskiwania ciekawych efektów artystycznych za pomocą warstw malarskich nakładanych od tyłu tafli tzw. techniką szkła odwróconego. Jako ostatnia w sekcji wypowiedziała się Johanna Cremer (Kolonia) analizująca motywy zdobnicze inspirowane bajkami i przysłowiami w referacie Sprichwörter und Fabeln auf Emailgläsern des 16. und 17. Jahrhunderts. 
Ukoronowaniem drugiego dnia sesji był wieczorny wykład Tadeusza Krzeszowiaka (Wiedeń), opatrzony tytułem Zur Wirkung von Glasfarblicht in höfischen Interieurs. Badacz specjalizuje się w studiach nad XVIII wiekiem, jest autorem m.in. monografii poświęconej teatrowi na przedmieściach Wiednia (tzw. Freihaustheater), w którym premierę miał Czarodziejski flet Mozarta. W odczycie konferencyjnym skoncentrował się na znaczeniu barwnych szkieł w wystroju i recepcji wnętrz rezydencjonalnych.

Ramanspektroskopie - Zerstörungsfreie Glasanalyse to tytuł referatu przedstawionego przez Gerharda Heide (Freiberg), otwierającego ostatni dzień obrad, a zarazem inaugurującego panel dedykowany metodom badawczym i obróbce szklanych wyrobów. Walorem przedstawionej przez prelegenta metody spektroskopowej jest fakt, że pozostaje ona bezpieczna dla analizowanej materii zabytkowej. Z kolei Werner Hiller-König (Karlsruhe) w wystąpieniu Korrosionsabläufe in neuzeitlichen Hohlgläsern, Benennung, Dokumentation und Sammlungsmanagement przybliżył słuchaczom zagadnienia związane z korozją szkła. Następnie głos zabrała Katrin Wittstadt (Wertheim) prezentująca temat Naturwissenschaftlich Forschung zum Erhalt von Kunstobjekten. Glasdosimetermessung zur Sicherung der barocken Emailpretiosen (Grünen Gewölbe Dresden) und Glasmalereien (Kölner Dom). Między innymi na przykładzie tytułowego skarbca z zamku drezdeńskiego badaczka ukazała techniki badania dozymetrem oraz zabezpieczania przed niszczeniem przedmiotów emaliowanych. Pokazane zostały też próby ochrony witraży. Kolejne dwa odczyty dotyczyły kolekcji zbiorów szklanych i ich konserwacji. Powyższy wątek poruszyli: Bettina Schneider (Berlin) w tekście Waschen, Legen, Föhnen - die digitale Erfassung der Glassammlung des Stadtmuseums Berlin oraz Annette Schommers i Hans-Jörg Ranz (Monachium) we wspólnym referacie Die Neupräsentation der Glassammlung des Bayerischen Nationalmuseums: Ausstellungskonzept - Didaktik - Präventive Konservierung.

W ostatnim, piątym panelu zebrano odczyty ukazujące znaczenie kolekcji i sposoby eksponowania zbiorów szkła artystycznego. Dzięki wystąpieniu Susanne Evers (Poczdam): „Glas Cammer” und „Gläser Spinde”. Fürstliche Glassammlungen und ihre Präsentation in den brandenburgisch-preußischen Schlössern von 1670 bis 1740 widoczny stał się sposób prezentacji szkieł w rezydencjach i aranżacji wystroju sal przeznaczonych do ich gromadzenia i pokazywania książęcym gościom. Christina Wais-Wolf (Wiedeń) w referacie Zur Frage der Medialität von Darstellungen habsburgischer Landesherren auf Fensterverglasungen des 16. und 17. Jahrhunderts starała się ukazać polityczne znaczenie tafli okiennych w kreowaniu i podkreślaniu kulturotwórczej roli dynastii cesarskiej. Blok wystąpień dopełniła analiza sposobów obrazowania szkła na malowidłach zawarta w prezentacji Bildliche Repräsentation von Glas - zur symbolischen und sozialen Bedeutung von Glasobjekten in frühneuzeitlichen Bildmedien autorstwa Philippa Zitzlspergera (Berlin). 


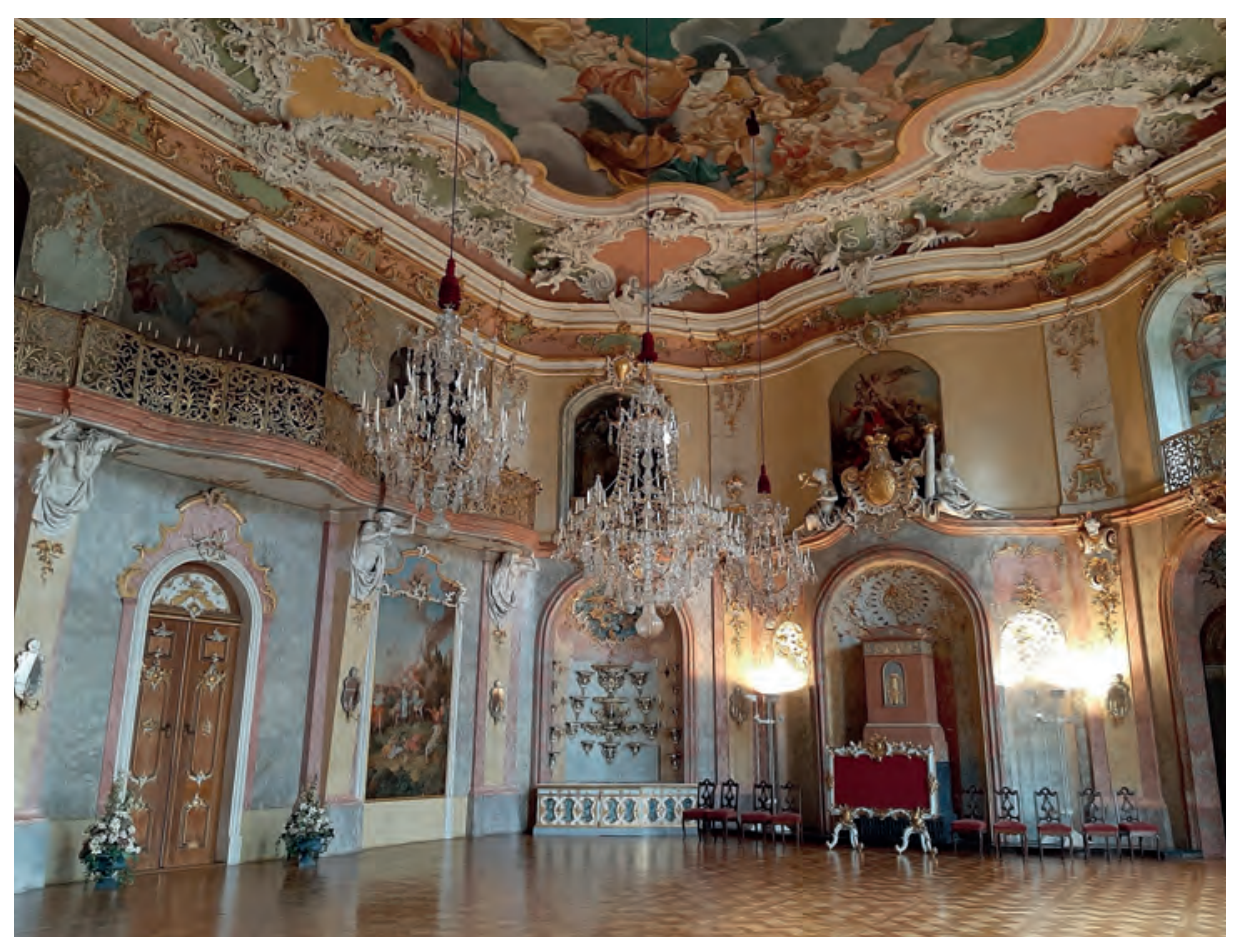

3. Rudolstadt, zamek Heidecksburg, fot. autorka, 2019

Obrady wzbogacono o wydarzenia towarzyszące, obejmujące m.in. koncert grany na szklanej harmonijce oraz wycieczkę do zamku Schwarzburg, W tej rezydencji goście mogli przyjrzeć się chociażby zbrojowni oraz sali cesarskiej. Szczególnie cenna była możliwość obejrzenia samego miejsca, w którym odbywała się konferencja - malowniczo położonego zamku Heidecksburg, należącego niegdyś do dynastii Schwarzburg-Rudolstadt. Rezydencję wzniesiono na miejscu wcześniejszego obiektu, który w 1735 roku w większości został strawiony przez pożar. Poza formą architektoniczną na uwagę zasługuje zachowany, oryginalny wystrój wnętrz utrzymanych w stylistyce rokokowej. Uczestnicy sesji mieli szansę przyjrzeć się chociażby słynnej sali balowej (il. 3).

Należy podkreślić rangę wydarzenia, które połączyło w sobie obchody jubileuszu dwudziestolecia istnienia stowarzyszenia Rudolstädter Arbeitskreis zur Residenzkultur z konferencją na wysokim poziomie merytorycznym. Referatom towarzyszyły długie i wnikliwe dyskusje, poświadczające potrzebę badań nad obiektami szklanymi. Unikatowy był wreszcie sam wybór tematu - obecność szkła w architekturze (np. tafle okienne), elementach wystroju wnętrz (np. żyrandole) i rzemiośle artystycznym (od instrumentów muzycznych po naczynia), który często pozostaje na marginesie badań nad dziejami sztuki lub analizowany jest na zasadzie studium przypadku. Tym cenniejsze stało się przekrojowe spojrzenie na szkło jako materiał obecny w tak licznych aspektach produkcji artystycznej doby nowożytnej. 